\title{
ПРОБЛЕМЫ ОБРАЗОВАНИЯ
}

Вестник ПСТГУ. Серия IV

Педагогика. Психология

2016. Bun. 4 (43). C. 9-23
Склярова Татьяна Владимировна, д- $\rho$ пед. наук, дочент, ПСТГУ

tsklyarova@mail.ru

Джероян Мария Сергеевна,

ПСТГУ

5009945@mail.ru

\section{ЦЕННОСТИ В СОВРЕМЕННОМ ШКОЛЬНОМ ОБРАЗОВАНИИ: ОПЫТ ВЕЛИКОБРИТАНИИ*}

\author{
Т. В. СКЛЯРОвА, М. С. ДЖЕРОян
}

\begin{abstract}
В статье анализируется опыт стандартизации школьного образования Великобритании по включению ценностей в содержание образования. Авторы выделяют четыре этапа с 1988 г. по настоящее время и связывают их с разработкой Единого учебного плана и реформой образования в Великобритании (1987-1988), принятием Закона об образовании и Национальным форумом ценностей (1992-1996), принятием Законов об образовании 2002, 2005 г. (2002-2005) и Закона о продвижении Британских ценностей в образовании 2014 г. (2014 - по наст. вр.). В работе приводятся фактические данные о реализации в школах Великобритании социального, культурного, духовного и нравственного воспитания/развития учащихся; характеризуются условия интеграции в школьное образование элементов религиозного образования и воспитания; приводятся примеры современного переосмысления концепции мультикультурализма, определения роли религии в современной школе и обществе, а также решения вопросов о том, каким образом светское государство должно поддерживать религиозное многообразие и терпимость.
\end{abstract}

\section{Актуальность исследования}

Осмысление перспектив модернизации школьного образования в нашей стране связано с процессами, на первый взгляд взаимоисключающими друг друга, - стандартизацией содержания, поиском аксиологических оснований для ведения учебно-воспитательной деятельности школы и вместе с тем созданием условий для поликультурного и межрелигиозного диалога. Введение федеральных государственных образовательных стандартов для всех уровней образования в России сопряжено с поиском ценностных оснований учебно-воспитательной работы образовательных учреждений, подтверждением чему являются Концепция духовно-нравственного развития и воспитания личности гражданина Рос-

* Работа выполнена при финансовой поддержке РГНФ, проект № 15-06-10300. 
сии ${ }^{1}$, Стратегия развития воспитания в России до 2025 г. $^{2}$, а также введение в содержание школьного образования предметов, связанных с изучением религиозных культур. В этой связи представляет интерес исследование того, как могут быть сопряжены цели, ценности и стандарты школьного образования в современных условиях. Анализ опыта развития системы школьного образования Великобритании, проделавшей с 1988 г. путь по его стандартизации с включением конкретных ценностей в содержание, сохранением религиозного образования в школе и созданием условий для межрелигиозного и поликультурного диалога, позволит сопоставить общие и особенные линии продвижения ценностей в образовании школьников Великобритании и России.

\section{Единый учебный план и реформа образования в Великобритании 1987-1988 г2.}

Модернизация школьного образования Великобритании началась в конце 1980-х гг. и была связана с усилением тенденции к централизации управлением системой общего образования. С 1944 по 1988 г. проблемы организации, содержания и оценки качества образования решались местными органами управления образованием. На государственном уровне решались только проблемы контроля качества работы школ, который осуществляли независимые от местных органов королевские инспекторы. В 1987 г. Департамент образования и науки издал «Единый национальный учебный план» (The National Curriculum), ставший составной частью принятого в 1988 г. «Закона о реформе системы образования». Данный закон о реформе образования сделал обязательным для всей страны «Единый национальный учебный план», учредил новые типы школ, расширил возможности выбора родителями учебного заведения для детей, что привело к формированию рынка образовательных услуг. The National Curriculum создал основания для разработки национальных стандартов по учебным предметам, что позволяет исследователям трактовать его как государственный образовательный стандарт среднего образования Великобритании․․ Реформа образования 1988 г. обязала все школы реализовывать в процессе обучения социальное, культурное, духовное и нравственное воспитание/развитие учащихся. Все предметы, преподаваемые в школе в рамках Единого национального учебного плана, должны предоставлять возможность учащимся духовно, нравственно, социально и культурно развиваться.

Духовное развитие ученика включает в себя рост самосознания, личных уникальных возможностей, понимание своих сильных сторон и недостатков и осознание желания стремиться к поставленным целям. В процессе духовного раз-

\footnotetext{
${ }^{1}$ Концепция духовно-нравственного развития и воспитания личности гражданина России. URL: http://mosmetod.ru/metodicheskoe-prostranstvo/nachalnaya-shkola/inklyuzivnoeobrazovanie/fgos/kontseptsiya-dukhovno-nravstvennogo-razvitiya-i-vospitaniya-lichnosti-grazhdaninarossii.html.

${ }^{2}$ Стратегия развития воспитания в России до 2025 года. URL: http://rg.ru/2015/06/08/ vospitanie-dok.html.

${ }^{3}$ См.: Вяземский E. E. Современная система образования в Великобритании // Новые исследования в образовании. Проблемы современного образования. 2010. № 6. С. 68-83.
} 
вития ученика все больше волнуют вопросы о своем месте в мире и назначении в жизни. В результате он приобретает знания, навыки и качества личности, необходимые для развития духовной жизни, выходящей за рамки поддержания материального существования.

Нравственное развитие ученика связано с приобретением им понятий о добре и зле, нравственном конфликте, необходимости заботы об окружающих, стремлении совершать правильные поступки. В процессе нравственного развития ученик вырабатывает способность отдавать себе отчет о последствиях своих поступков, учится прощать себя и других. В результате он приобретает умения, навыки, знания и личностные качества, необходимые для принятия ответственных моральных решений и готовность действовать в соответствии с ними.

Социальное развитие ученика подразумевает приобретение им понимания своих обязанностей и прав как члена семьи и сообщества (местного, национального и глобального), способности взаимодействовать с окружающими и работать в команде во имя общей цели. В процессе социального развития учащиеся демонстрируют чувство принадлежности и растущее желание участвовать в общественной жизни. В результате они приобретают знания, навыки и личностные качества, необходимые для реализации собственной активности в обществе.

Культурное развитие ученика связано с приобретением им понимания культурных традиций и способности ценить разнообразие эстетических практик. В процессе культурного развития он начинает уважать собственную культуру и культуру других людей, интересуется тем, как можно по-разному делать одно и то же. Различия вещей и культурные отличия народов вызывают у него любопытство, а не раздражение. В результате он приобретает умения, навыки, знания и личностные качества, необходимые для того, чтобы ценить культуру и вносить в нее свой вклад ${ }^{4}$.

Большие возможности для поддержания развития в данных областях предоставляются школьникам в курсах религии, граждановедения и не закрепленных законодательно рекомендациях по личностному, социальному и физическому здоровью (Personal, Social and Health Education).

Школам была предоставлена свобода в выборе содержания и методов осуществления указанных направлений развития школьников, однако обязанности школы в реализации учебного плана были четко зафиксированы. В первую очередь, школа должна самостоятельно разработать принципы для различения правильного и неправильного социального, культурного, духовного и нравственного воспитания/развития учащихся. Духовное развитие учащихся связано с формированием в системе их мировоззрения и усвоением в деятельности непреходящих ценностей, к которым были отнесены ценности добродетели, правды, справедливости, честности, доверия и чувства долга ${ }^{5}$. В процессе реализации Единого учебного плана педагогический коллектив школы был призван:

${ }^{4}$ Материалы подготовлены специалистами Министерства образования и профессиональной подготовки и Агентства по стандартам и квалификациям (Великобритания, 2005 г.). URL: www.dfes.gov.uk и www.nc.uk.net. (пер. с англ. А. Пинской).

${ }^{5}$ Handbook for secondary teachers in England www.nc.uk.net Key stages 3 and 4 Revised 2004. URL: http://www.education.gov.uk/publications/eOrderingDownload/QCA-04-1374.pdf. 
- развивать знания школьников, понимание и оценку ими своих собственных и иных верований и культур;

- воспитывать и развивать способность школьников к анализу влияния религии и культуры на человека и общество;

- знакомить школьников с непреходящими (духовными) ценностями, развивать их самостоятельность, ответственность, способность и готовность вносить вклад в развитие общества;

- способствовать равному проявлению возможностей для каждого, позволять учащимся бороться с дискриминацией и стереотипами;

- развивать у учащихся уважение к той среде, в которой они живут, обеспечивая возможность их развития на личном, местном, национальном и глобальном уровнях;

- предложить учащимся инструментарий, благодаря которому они смогут осознавать свои права и обязанности, самостоятельно принимать решения и обосновывать собственные суждения;

- улучшать эмоциональное благополучие учащихся, в том числе повышением их самооценки;

- способствовать формированию и поддержке позитивных отношений в семье, школе, на работе и в обществе в целом, основанных на уважении себя и других людей;

- развивать коммуникативные способности учащихся и их готовность работать для общего блага;

- развивать у учащихся способность позитивно реагировать на неприятности, перемены, необходимость принятия на себя ответственности;

- подготовить учащихся к самоопределению в сферах образования и трудовой занятости по окончании школы;

- дать возможность учащимся делать осознанный выбор как в школе, так и на протяжении всей жизни, оценивая значимость своих достижений в жизни и обществе за пределами школы ${ }^{6}$.

Приведенные выше требования по выполнению The National Curriculum подтверждают тот факт, что стандарт регламентирует не то, что школьники должны знать, а то, что они должны уметь делать и к выполнению чего быть готовыми. Ключевые умения (Key Skills) являются предметом педагогического управления и представлены в виде так называемых уровней достижений (Levels of attainment) для каждой возрастной ступени школьного образования. Конкретика процессуально-деятельностного компонента содержания образования отражает не столько содержание включаемого в школьные предметы учебного материала, сколько характер и уровень познавательной деятельности школьника. Этому призваны способствовать межпредметные элементы (Learning across the National Curriculum), которые нацелены на интеграцию процессов социального, культурного, духовного и нравственного воспитания/развития учащихся. Они представлены в форме обобщенных идей и тем, а также универсальных умений учащихся (расширенный аналог универсальных учебных действий в российском образовании). Интеграция социального, культурного, духовного и нравственно-

${ }^{6}$ См.: Handbook for secondary teachers in England www.nc.uk.net Key stages 3 and 4 Revised 2004. 
го воспитания/развития учащихся нацелена в конечном итоге на формирование личностного, социального и физического здоровья/благополучия (Personal, Social and Health Education) учащихся и становление их гражданственности ${ }^{7}$

\section{Закон об образовании и Национальный форум ценностей 1992-1996 г2.}

Последующая централизация управления образованием в Великобритании была связана с принятием в 1992 г. Закона об образовании и и созданием в 1993 г. Управления по стандартам в сфере образования (OFSTED), которому делегированы полномочия инспектирования и оценки качества обучения в школах и подготовки педагогических кадров. Инспекция качества обучения в школах проверяет реализацию единого учебного плана, уровень учебных достижений школьников, а также оценивает воспитательное пространство школы, специально организованный социально-психологический климат, который иногда называют «скрытым учебным планом». Управление по школьным учебным планам и процедурам оценки (School Curriculum and Assessment Authority - SCAA) учредило национальный форум ценностей, задачей которого стало обсуждение и выработка консолидированного решения о том, какие ключевые ценности призвано формировать школьное образование. В 1996 г. 150 представителей различных слоев общества Великобритании собрались в Лондоне для обсуждения вопросов о ценностях в школьном образовании. Национальный форум ценностей сформулировал подходы к определению общих, независимо от религиозных и этических взглядов, ценностей, которые должны присутствовать в системе школьного образования Великобритании. Участникам форума необходимо было решить, существуют ли в современном обществе ценности, приемлемые для всех его членов, или есть такие ценности, которым еще предстоит быть согласованными со всеми членами общества. Они составили список ценностей, который Центр изучения общественного мнения (MORI) отправил на согласование в 3200 школ и 700 организаций национального значения, а также был проведен опрос среди 1500 взрослых. 97\% опрошенных согласились с данным списком (Findings of the consultation on values in education and the community, 1996). Форум декларировал положение о том, что принятые им ценности не являются исчерпывающими. Они не могут быть основаны на религиозных убеждениях, принципах или учениях, хотя и должны быть связаны с источниками общепринятых ценностей. Названные ценности не являются единственными, и это означает, что школы не обязаны ограничиваться только ими. Декларация форума ценностей исходила из того, что принятый им список ценностей призван быть разделяемым всеми членами общества и совместимым с различными источниками происхождения ценностей. С этой целью был избран подход, который не противоречил бы двум взаимоисключающим точкам зрения на происхождение ценностей. С одной стороны, участники форума признали правомочность представлений о существовании Бога как абсолютного источника ценностей и ответственности человека

${ }^{7}$ CM.: Handbook for secondary teachers in England www.nc.uk.net Key stages 3 and 4 Revised 2004.

${ }^{8}$ Further and Higher Education Act 1992. URL: http://www.legislation.gov.uk/ukpga/1992/13. 
перед Богом. С другой стороны, были признаны и представления нерелигиозной части населения о том, что ценности имеют своим источником только природу человека, и человек ответственен за них только перед лицом своей совести. Названные ценности должны быть совместимы с разного рода их толкованиями и применением. На усмотрение каждой школы остается вопрос, как эти ценности могут быть интерпретированы и использованы в процессе воспитания учащихся. Основываясь на названных подходах, форум определил четыре ценностные сферы: ценности личности, отношений, общества и окружающей среды. Предложенный порядок перечисления ценностей не подразумевает какого-либо приоритета или предпочтений, но отражает убеждение многих, что осознание ценности личности должно предшествовать развитию других ценностей 9 .

Детальная характеристика каждой из названных сфер также была разработана в логике описания деятельности и личностных установок школьников, которые должны быть усвоены. Приведем данные характеристики, зафиксированные в документах форума ${ }^{10}$.

Ценность личности. Мы ценим себя как уникального человека, способного духовно-нравственно, интеллектуально и физически расти и развиваться. На основе этих ценностей мы должны:

- развивать понимание своей личности, ее сильных и слабых сторон;

- развивать самоуважение и самодисциплину;

- прояснять смысл и цель своей жизни и, исходя из этого, решать, как должна быть прожита наша жизнь;

- ответственно использовать свои таланты, права и возможности;

- стремиться в течение всей жизни к знаниям, пониманию и мудрости;

- в рамках своих возможностей брать на себя ответственность за собственную жизнь.

Ценность отношений. Мы ценим других за то, какие они есть, а не за то, что они имеют или могут сделать для нас. Мы ценим отношения с другими людьми, потому что они являются основой для нашего развития и реализации на благо сообщества и нас, и других. На основе этих ценностей мы должны:

- уважать других, в том числе детей;

- заботиться о других, проявлять доброжелательность в отношениях с ними;

- показывать другим, как они ценны для нас;

- выработать уверенность в отношениях с другими, заработать их доверие и лояльность;

- уважать частную жизнь и собственность других людей;

- работать совместно с другими;

- решать спорные вопросы мирным путем.

${ }^{9}$ Cм.: School Curriculum and Assessment Authority // Education for Adult Life: The Spiritual and Moral Development of Young People: A Summary Report, SCAA. L., 1996. Discussion papers № 6.

${ }^{10}$ SCAA (1996b) The National Forum for Values in Education and the Community: Consultation on Values in Education and the Community. L., SCAA. 
Т. В. Склярова, М. С. Джероян. Ценности в современном школьном образовании: опыт Великобритании

Ценность общества. Мы ценим правду, свободу, справедливость, права человека, верховенство права и коллективные усилия для общего блага. В частности, мы ценим семью как источник любви и поддержки для всех ее членов, а также как основу общества, в котором люди заботятся о других. На основе этих ценностей мы должны:

- понимать и выполнять свои гражданские обязанности;

- не принимать идеи и отказаться от действий, которые могут быть опасными для людей или сообществ;

- поддерживать семьи в воспитании детей и уходе за иждивенцами;

- поддерживать институт брака;

- признавать, что любовь и самоотдача необходимы для безопасного и счастливого детства;

- уважать верховенство закона и поощрять других делать так;

- помогать людям узнать о законе и правовых процессах;

- уважать религиозное и культурное многообразие;

- предоставлять равные возможности для всех;

- поддерживать тех, кто не может сам поддерживать достойный образ жизни;

- поощрять участие в демократическом процессе всех слоев общества;

- вносить свой вклад в экономические и культурные процессы;

- принимать истину, целостность, честность и доброжелательность приоритетов общественной и личной жизни.

Ценность окружающей среды. Мы ценим природную и созданную человеком окружающую среду как основу жизни, источник чудес и вдохновения. На основе этих ценностей мы должны:

- принять нашу ответственность за поддержание сохранной окружающей среды для будущих поколений;

- понимать место и роль человека в природе;

- понимать наши обязанности перед животным и растительным миром;

- сохранять баланс и разнообразие в природе везде, где это возможно;

- сохранять красивые места для будущих поколений;

- восстанавливать, где это возможно, места обитания, поврежденные деятельностью человека и другими способами.

На основе названных групп ценностей, обозначенных форумом, в течение полугода было разработано руководство для школ по реализации духовнонравственного, социального и культурного воспитания школьников. Управление по школьным учебным планам и процедурам оценки учредило совет из учителей, директоров, дидактов, религиозных лидеров, совета родителей и других организаций, которые приняли участие в составлении этого руководства ${ }^{11}$.

Руководство устанавливает последовательность действий школы по воспитанию ценностей:

\footnotetext{
${ }^{11}$ School Curriculum and Assessment Authority (1996b) // The National Forum for Values for Values in Education and the Community: Final Report and Recommendations, SCAA/96/43, L.: SCAA.
} 
- совместно с местными сообществами определить ценности для данной школы и выявить ключевые стадии соотнесения их с духовно-нравственным, социальным и культурным воспитанием школьников;

- определить конкретные задачи для каждой ключевой стадии;

- оценить, каким образом могут быть достигнуты: а) текущий успех и б) возможности для дальнейшей работы;

- выполнить намеченное;

- оценить процесс и полученные результаты;

- выявить и поощрить успешных участников процесса как из числа учеников, так и из числа взрослых.

Таким образом, школа сама вправе прописывать продвижение тех ценностей, которые удовлетворяли бы всех участников образовательного процесса. Выбранные школой ценности часто совпадают с теми, что обозначены форумом ценностей.

\section{Законы об образовании 2002, 2005 г2.}

Законодательно закреплено государственное инспектирование школ, нацеленное на проверку соответствия развития духовных ценностей школьников принятым стандартам. После 2002 г. в обществе снижается интерес к обсуждению ценностей, которые должны входить в содержание школьного образования, сокращается число публикаций в педагогической литературе и прессе, посвященных ценностным основаниям образования. Сложившаяся в этот период система инспектирования школ предусматривает значительную свободу школы в реализации ценностного воспитания. Государственные, частные и религиозные школы могут выбирать ценностный базис, на котором строится образовательный процесс. Главное - это соблюдение всеми школами Единого национального учебного плана, не оставляющего места для преподавания откровенно антинаучных взглядов и/или нетерпимости к другим религиям. Основные формы ценностного воспитания обеспечиваются тремя ведущими направлениями деятельности школы:

- организацией общешкольной молитвы (коллективного поклонения),

- созданием благоприятного социально-психологического климата школы,

- организацией соответствующей внеурочной деятельности.

Общешкольная молитва (коллективное поклонение) установлена Законом об образовании 1988 г., утвердившим обязательность коллективного поклонения в школе. В соответствии с Законом общешкольная молитва должна быть направлена на предоставление учащимся возможности поклоняться Богу, изучать духовно-нравственные вопросы и формировать собственные убеждения, развивать дух коллективизма, укрепляя позитивное отношение к общим ценностям, активно участвуя в коллективном поклонении.

Коллективное поклонение призвано объединять всех учащихся школы, независимо от их личной веры. Оно отличается от молитвенного собрания верующих определенной конфессии. Родители имеют право освободить своих детей от совместной молитвы по причине отличия семейных религиозных представ- 
лений. Тем не менее ребенок должен присутствовать на части общего собрания, где озвучивается общешкольная информация и делаются соответствующие комментарии. От совместной молитвы ребенок может отказаться. Родители имеют право на время общешкольной молитвы предоставлять ребенку информацию и материалы, относящиеся к собственной вере. Педагоги также имеют право не посещать общешкольную молитву в соответствии с собственными религиозными убеждениями. Минимум раз в неделю коллектив должен собираться на общешкольную молитву. Коллективное поклонение может быть организовано в классной комнате или общем холле школы. На нем может присутствовать один класс, учащиеся одной ступени (например, только начальной школы) или все школьное сообщество. Коллективное поклонение должно соответствовать возрастным и индивидуальным особенностям учащихся в каждой школе и не должно противоречить их семейным традициям. Ответственность за выполнение этих требований лежит на завуче, который должен определить формат коллективного поклонения после консультаций с руководящим органом. Если школа окажется не в состоянии соответствовать требованиям законодательства, руководители школ должны разработать соответствующий план действий. Большинство актов коллективного поклонения в школе должны в основном иметь общехристианский характер (но не содержание), отражающий единство традиции христианской веры, но не какой-либо конкретной христианской конфессии. В течение семестра общешкольная молитва может отражать как общехристианские традиции, так и традиции других религий, например, во время празднования Дивали или Ураза-Байрам. Особенно это рекомендуется проводить в школах с многоконфессиональным составом учащихся. Во время коллективного поклонения школьникам должны быть предоставлены условия для спокойного размышления или возможность для личной молитвы. Коллективное поклонение вне школьных помещений, например, в церкви на рождественской службе, организуется с разрешения руководящих органов и не заменяется обязательными еженедельными общешкольными молитвами на территории школы. Коллективное поклонение не связано с уроками религии в школе, организация и координация общешкольной молитвы не ложится автоматически на учителя религии. Единственная возможная связь между уроками религии и коллективным поклонением может проявляться в согласовании учебного плана с темами общешкольной молитвы. На проведение коллективного поклонения отводится примерно 15 минут в день, это событие может проводиться в любое время в течение школьного дня. Активизации участия школьников призваны способствовать разнообразие содержания и представленности коллективного поклонения (каждый раз новые ведущие, гости, привлечение артефактов, увлекательные рассказы, музыка, видеоматериалы, картины, свечи) и также вовлеченность учащихся в содержание мероприятия (они могут быть ведущими, читать стихи или молитвы, ставить миниспектакли, поощряется задавать вопросы и отвечать на них).

Благоприятный социально-психологический климат школы характеризует школьную среду, в которой есть место для духовного, нравственного, социального и культурного развития школьников. Создается и оценивается посредством: 
- ценностей, которые исповедуют своим поведением сотрудники, руководство и учащиеся;

- складывающимися отношениями между педагогами и школьниками;

- способами решения конфликтных ситуаций;

- физическими характеристиками материальной среды;

- возможностями, предоставляемыми школой за рамками выполнения учебного плана;

- связями школы с другими сообшествами;

- характером материалов, публикуемых в школе ${ }^{12}$.

Организация внеурочной деятельности дополняет обязательные уроки религии, граждановедения и уроки здоровья/благополучия (Personal, Social and Helth Education).

Уроки и внеурочная деятельность планируются и оцениваются с точки зрения духовного, нравственного, социального и культурного развития школьников. Так, уроки религии (религиозного воспитания) помогают учащимся:

- рассмотреть и ответить на вопросы, связанные со смыслом и целями жизни, изучить вопросы о природе ценностей в человеческом обществе (духовный аспект);

- принимать ответственные решения с помощью своих знаний и понимания религиозного и/или этического учения (нравственный аспект);

- развивать свое чувство идентичности и принадлежности (социальный аспект);

- знакомят с разнообразием убеждений и религиозных практик, расширяя представления о культурном контексте, в котором живут люди (культурный аспект).

Уроки граждановедения нацелены на продвижение духовного, нравственного, социального и культурного развития школьников.

Ведущий концепт этих уроков основан на изучении демократии и законности, прав и обязанностей, общности и различий для совместной жизни в Великобритании. В процессе обучения школьникам предстоит выработать потребность и умение критически мыслить, навыки самопрезентации и представительской деятельности, принимать обоснованные и ответственные решения.

Уроки здоровья/благополучия нацелены на последовательное развитие духовности, нравственности, социальной активности и развития культуры школьников. Ведущий концепт этих уроков основан на знакомстве с культурой взаимоотношений, здорового образа жизни, разнообразия в мире, личной самоидентичности и рискованного поведения. В процессе обучения школьникам предстоит выработать умение критически мыслить, развивать взаимоотношения и сотрудничество с другими, принимать решения, осознавать их последствия, в том числе последствия рискованного поведения.

${ }^{12}$ Promoting and evaluating pupils' spiritual, moral, social and cultural development. URL: http://www.gloucester.anglican.org/content/pages/documents/1354799219.pdf. 
Т. В. Склярова, М. С. Джероян. Ценности в современном школьном образовании: опыт Великобритании

«Троянский конь» в Бирмингеме и Закон

о продвижении Британских ценностей в образовании 2014 г.

В начале 2014 г. власти Бирмингема и представители прессы получили анонимное послание, в котором подробно описывался план «Троянский конь». В Бирмингеме более $20 \%$ населения исповедуют ислам, в некоторых районах города мусульмане составляют большинство, среди школьников коренные англичане - в меньшинстве. Именно в этом городе сложилась благоприятная среда для перехода большинства городских школ под контроль исламистов, что и составляло суть плана «Троянский конь». План предусматривал введение сторонников исламизма в попечительские советы школ, смену директоров и иных руководителей образовательных учреждений на том основании, что они заставляют учащихся читать христианские молитвы, заниматься плаванием и спортом, развращают детей сексуальным просвещением и рассказами о гомосексуализме. Движущей силой выполнения плана должны были стать активисты различных мусульманских некоммерческих организаций - благотворительных и образовательных. Главная цель - «обеспечить, чтобы эти школы руководствовались строгими предписаниями ислама» ${ }^{13}$.

Управление по стандартам в сфере образования (Ofsted) провело инспектирование школ Бирмингема, в ходе которого были обнаружены и доказаны факты нарушений, движущей силой которых стала исламистская политическая идеология. Всего в Бирмингеме более 300 школ, подозрения в участии в заговоре коснулись 25 школ, 6 из которых, как утверждается, полностью перешли под контроль исламистов. Они получили по итогам отчета школьной инспекции неудовлетворительную оценку, что повлекло за собой введение внешнего управления и отстранение руководства, включая попечительские советы. В этих школах сложилась неблагоприятная обстановка, связанная с фактическим отказом формировать у учеников научную картину мира при повышенном внимании к урокам ислама. Согласно свидетельствам, учителя скороговоркой рассказывают на уроках теорию Дарвина, но затем говорят «на самом деле мы в это не верим». Преподавание основ религий на практике сводится к обучению исламу. В некоторых школах введено фактически обязательное изучение арабского языка при полном игнорировании английской литературы и культуры. Исламизация школ проявляется и во внешнем оформлении классов, и в практике сегрегации (девочки сидят в классах отдельно от мальчиков, мусульмане от немусульман - причем не по собственной воле, а по указанию учителей). Наконец, исламизация касается и внеклассной деятельности. Так, в школе Park View перед учениками выступал известный антисемитскими взглядами и одобрением деятельности «Аль-Каиды» радикальный проповедник Шейх Шади аль-Сулейман, призывавший побивать геев камнями. В некоторых школах фактически под запретом находится Рождество, поощряются насмешки над христианскими верованиями. Инспекторы отметили, что из некоторых школ были вынуждены уволиться учителя и прежние руководящие работники, поскольку новые попечительские советы и директора создавали им невыносимые условия для работы. Отказывавшиеся увольняться

\footnotetext{
${ }^{13}$ «Троянский конь» исламизма. URL: http://www.svoboda.org/a/25359609.html.
} 
учителя начали получать угрозы в свой адрес. Еще в нескольких проинспектированных школах Бирмингема ситуация была признана не столь критической, но было отмечено, что они тоже находятся под угрозой.

История с бирмингемским «троянским конем» побудила правительство Великобритании заняться разработкой более прозрачной системы управления публичными школами и контролем за ними, переосмыслить концепцию мультикультурализма, а также решить, какую роль продолжает играть религия в школе и обществе и каким образом светское государство должно поддерживать религиозное многообразие и терпимость.

В сентябре 2014 г. OFSTED обновил руководство по инспекции школ ${ }^{14}$. Был сформулирован список основополагающих британских ценностей, которые должны быть представлены в содержании школьного образования, - дeмократия, личная свобода, главенство закона, взаимное уважение и терпимость к представителям разных вероисповеданий. С этого времени все поддерживаемые государством школы должны способствовать научению учащихся названным ценностям, благодаря чему школьники должны понимать, что все граждане Beликобритании находятся под одним законом, несмотря на различия взглядов о том, что есть «правильно» и «неправильно». Если школы учат религиозным законам, особое внимание следует уделить прояснению отношений между государственным и религиозным законом. Учащиеся должны осознавать разницу между законом государства и религиозными законами.

Управление по стандартам в сфере образования обновило также руководство для школ по духовно-нравственному, социальному и культурному развитию учащихся.

Духовное развитие учащихся проявляется в:

- способности осмысливать собственные религиозные или иные убеждения, касающиеся взглядов на жизнь, уважения к людям, имеющим различные верования и ценности;

- позитивном отношении к познанию самого себя, других людей и окружающего мира;

- активной работе воображения и творчества в процессе обучения.

Нравственное развитие учащихся проявляется в:

- умении распознавать разницу между правильным и неправильным, способности применять это умение в собственной жизни, уважая гражданский и уголовный закон Англии;

- осознании последствий собственных действий и поведения;

- способности обосновывать свою позицию по моральным и этическим вопросам, готовности к анализу и оценке точек зрения других людей на эти вопросы.

Социальное развитие учащихся проявляется в:

- умении пользоваться широким спектром социальных навыков, в том числе во взаимодействии и общении с учениками из разных религиозных, этнических и социально-экономических слоев;

${ }^{14}$ https: //www.gov.uk/government/publications/the-framework-for-school-inspection 
Т. В. Склярова, М. С. Джероян. Ценности в современном школьном образовании: опыт Великобритании

- готовности к сотрудничеству с другими, участию в жизни различных общин в разнообразных социальных условиях, в том числе путем волонтерства;

- способности эффективно решать конфликты;

- принятии основополагающих британских ценностей, готовности к полноценному участию в жизни современной Британии.

Культурное развитие учащихся проявляется в:

- осознанном уважении широкого спектра культур, сформировавших их собственное мировоззрение и представляющих наследие других культур;

- готовности к принятию разнообразного диапазона культур, представленного в школе и отражающего жизнь современной Британии;

- знании демократической парламентской системы Великобритании и ее центральной роли в формировании традиций развития Великобритании;

- готовности позитивно воспринимать и участвовать в художественных, спортивных и культурных мероприятиях;

- проявлении уважения и интереса к изучению различных религий и культурного многообразия;

- толерантном отношении к различным религиозным, этническим и социально-экономическим группам в местных и глобальных сообществах.

Контроль за качеством работы школ возложен на независимых от местных властей инспекторов Управления стандартами в образовании (OSTFED), куда входят специалисты по отдельным предметам и один член группы, не имеющий опыта преподавания или управления школами. Каждая школа инспектируется один раз в четыре года. Оценка работы школы проводится по следующим критериям:

- Превосходно.

Осознанное и всестороннее продвижение школой духовного, нравственного, социального и культурного развития учащихся и их физического благополучия, что позволяет им благоприятно развиваться в сплоченном учебном коллективе.

- Хорошо.

Реализуются эффективные меры по созданию сплоченного учебного коллектива путем продвижения духовного, нравственного, социального и культурного развития учащихся и их физического благополучия. Существует позитивный социально-психологический климат в школе.

- Требуются улучшения.

Школа нуждается в улучшении, потому что одна или более из четырех основных позиций недостаточно проявлены в продвижении духовного, нравственного, социального и культурного развития учащихся.

- Не отвечает требованиям.

Серьезные недостатки в продвижении духовного, нравственного, социального и культурного развития учащихся и/или их физического благополучия проявляются в том, что ученики нетерпимы к другим и/или отклоняют любую из основополагающих ценностей современной Британии.

Приведенные в данной работе фактические данные о различных этапах интеграции ценностного ядра в содержание школьного образования Великобритании позволяют сделать следующие выводы: 
- духовное воспитание (развитие) школьников включено в процессы стандартизации образования наряду с нравственным, социальным и культурным воспитанием (развитием);

- религиозное образование и воспитание интегрируются в содержание учебно-воспитательной деятельности школы при соблюдении ряда условий, которые инспектирует государство;

- первоначально государственное попечение направлено на выработку ценностного ядра (списка ценностей) в содержании образования, затем постепенно внимание государственной инспекции смещается на подготовку педагогов и в итоге - на соблюдение прозрачности в деятельности школ по духовному воспитанию (развитию) учащихся;

- концепция мультикультурализма в содержании школьного образования подвергается переосмыслению в плане решения вопросов о том, какова роль религии в школе и обществе и каким образом светское государство должно поддерживать религиозное многообразие и терпимость;

- духовное воспитание школьников, включающее религиозное воспитание, нацелено преимущественно не на воспроизводство традиции, а на развитие способности и готовности учащихся отвечать вызовам современности.

Ключевые слова: религиозное образование, религиозное воспитание, духовное развитие школьников, содержание образования, ценности в содержании образования.

\section{VALUES in EdUCATION: EXPERIENCE OF THE UK}

\section{T. SkLyarova, M. Dzheroyan}

The study analyzes the experience of promoting values in the contents of education in the UK. The authors identify four stages from 1988 to present and associate them with the development of a Unified curriculum and Education Reform Act in the UK (1987-1988); the adoption of the Education Law and the National Forum for Values (1992-1996); the adoption of Education Laws in 2002 and in 2005 (2002-2005); and the adoption of the Law on promoting British values in education in 2014 (2014 to present). The paper represents actual data on promoting social, cultural, spiritual and moral development of pupils in British schools; characterizes the conditions of promoting religious education in school; gives examples of modern rethinking of the concept of multiculturalism, the role of religion in modern school and society, as well as the issues on how a secular state should support religious diversity and tolerance.

Keywords: religious education, religious education, and spiritual development of pupils, content of education, values in the content of education. 


\section{Список литературы}

1. Вяземский E. E. Современная система образования в Великобритании // Новые исследования в образовании: Проблемы современного образования. 2010. № 6. С. 68-83.

2. Концепция духовно-нравственного развития и воспитания личности гражданина России. URL: http://mosmetod.ru/metodicheskoe-prostranstvo/nachalnaya-shkola/ inklyuzivnoe-obrazovanie/fgos/kontseptsiya-dukhovno-nravstvennogo-razvitiya-ivospitaniya-lichnosti-grazhdanina-rossii.html.

3. Стратегия развития воспитания в России до 2025 года. URL: http://rg.ru/2015/06/08/ vospitanie-dok.html.

4. «Троянский конь» исламизма. URL: http://www.svoboda.org/a/25359609.html.

5. Further and Higher Education Act 1992. URL: http://www.legislation.gov.uk/ukpga/1992/ 13.

6. Handbook for secondary teachers in England www.nc.uk.net Key stages 3 and 4 Revised 2004. URL: http://www.education.gov.uk/publications/eOrderingDownload/QCA-04-1374.pdf.

7. Promoting and evaluating pupils' spiritual, moral, social and cultural development. URL: http://www.gloucester.anglican.org/content/pages/documents/1354799219.pdf.

8. SCAA (1996b) The National Forum for Values in Education and the Community: Consultation on Values in Education and the Community. L.: SCAA.

9. School Curriculum and Assessment Authority (1996) Education for Adult Life: The Spiritual and Moral Development of Young People: A Summary Report, SCAA, Discussion papers № 6.

10. School Curriculum and Assessment Authority (1996b) // The National Forum for Values for Values in Education and the Community: Final Report and Recommendations, SCAA/96/43, London: SCAA. 